\title{
Survey on Biomedical Applications of Cooperative Communication
}

\author{
Preethi Pattabiraman \\ PG Scholar \\ Department of Computer Science\&Engg., \\ Velammal Engineering College Chennai
}

\author{
R. Dhaya, $\mathrm{PhD}$ \\ Associate Professor \\ Department of Computer Science \&Engg., \\ Velammal Engineering College Chennai
}

\begin{abstract}
Cooperative communication is a multi-antenna technique for optimising or maximising the channel capactities of a given network with the help of user cooperation. The key idea in user cooperation is resource-sharing among multiple nodes in the network, with the willingness of sharing power and other network resources. This concept of multi-user MIMO (Multiple Input Multiple Output)can be applied in the field of medicine. Medical information have higher priority in communication networks. This survery paper analyses on the possibilities and difficulties of applying cooperative communication in biomedical field.
\end{abstract}

\section{Keywords}

Cooperative communication, Biomedical, healthcare, MIMO

\section{INTRODUCTION}

In cellular applications, a mobile station (MS) usually communicates directly with a base station (BS). MSs compete for resources, since they use 'single-hop' strategy, sending data directly to the destination which is called as singlr hop networks is shown in left side of Figure 1.

In multi-hop networks, devices send their data via a number of "helpers", the "relay" nodes to their destination. This relay improves energy efficiency and robustness to fading and failure of individual devices along the path of source and destination, which is shown in right side of Figure 1.

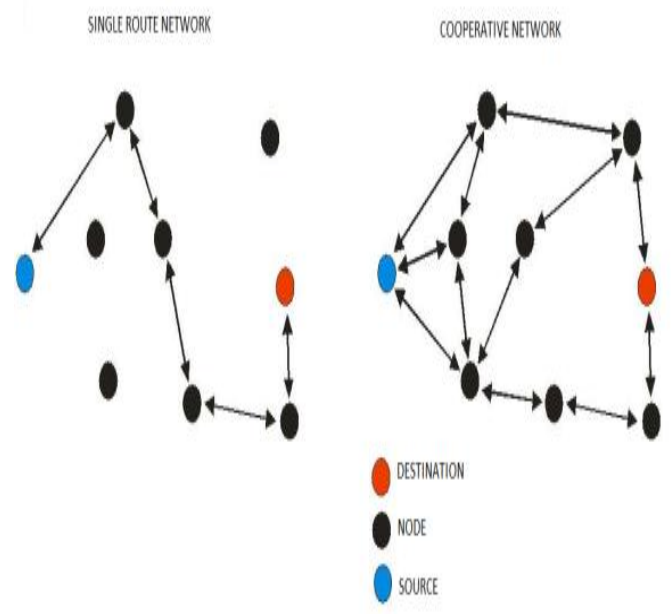

Figure 1 A single hop network vs. cooperative network

\subsection{Building Blocks}

A cooperative communication system consists of a transmitter, a number of parallel relays and a destination or a receiver, as given in Figure 2. There are possibilities of multiple transmitters and multiple receivers (MIMO). In cooperative communication, more than one cooperative user gets transmitted signal copies and retransmits those copies of data towards destination. These users are relay nodes. Thus the signal or data from source node follows individual transmission paths over shorter distances in wireless communication with low power requirement and more reliability.
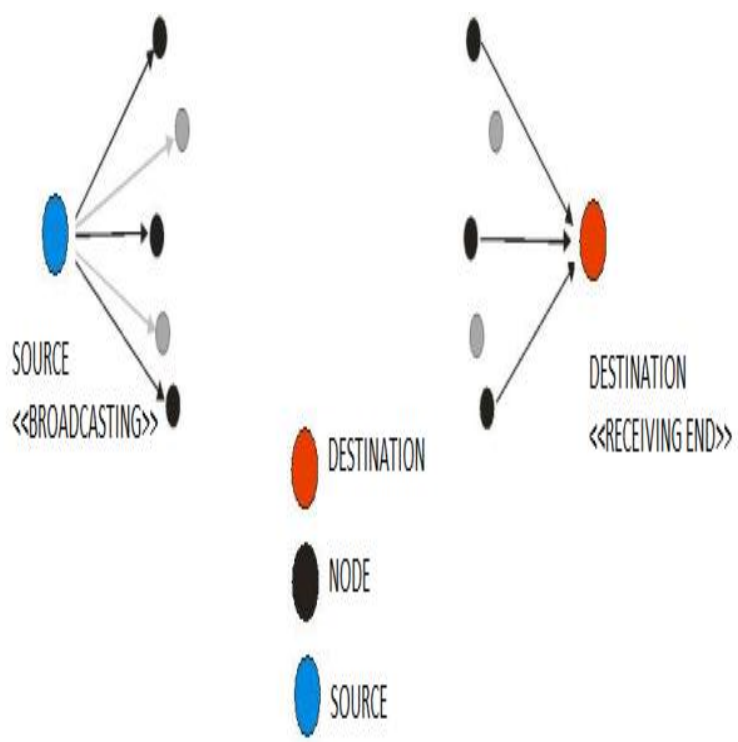

Figure 2 Basic Building blocks of a cooperative communication system

\section{LITERATURE SURVEY}

The table below, Table 1 lists some papers referred for preparing this survey paper:

Table 1: Papers related to Cooperative Communication and its applications

\begin{tabular}{|c|c|c|c|c|}
\hline Publication & Topic & Author & $\begin{array}{l}\text { Yea } \\
\mathbf{r}\end{array}$ & Work \\
\hline $\begin{array}{l}\text { Conference } \\
\text { on } \\
\text { Advances } \\
\text { in } \\
\text { Communica } \\
\text { tion and } \\
\text { Control } \\
\text { Systems }\end{array}$ & $\begin{array}{l}\text { Advance } \\
\text { d } \\
\text { Applicati } \\
\text { ons } \\
\text { using } \\
\text { Cooperat } \\
\text { ive } \\
\text { Wireless } \\
\text { Network } \\
\text { s }\end{array}$ & $\begin{array}{l}\text { S.R.Diko } \\
\text { ndwar, } \\
\text { Gautam } \\
\text { Chopra }\end{array}$ & $\begin{array}{l}201 \\
3\end{array}$ & $\begin{array}{l}\text { This paper } \\
\text { proposes } \\
\text { some alg. for } \\
\text { various } \\
\text { applications } \\
\text { of } \\
\text { cooperative } \\
\text { communicatio } \\
\text { n. }\end{array}$ \\
\hline Conference & Advance & S.R.Diko & 201 & This paper \\
\hline
\end{tabular}




\begin{tabular}{|c|c|c|c|c|}
\hline $\begin{array}{l}\text { on } \\
\text { Advances } \\
\text { in } \\
\text { Communica } \\
\text { tion and } \\
\text { Control } \\
\text { Systems } \\
2013\end{array}$ & $\begin{array}{l}\mathrm{d} \\
\text { Applicati } \\
\text { ons } \\
\text { using } \\
\text { Cooperat } \\
\text { ive } \\
\text { Wireless } \\
\text { Network } \\
\text { s }\end{array}$ & $\begin{array}{l}\text { ndwar, } \\
\text { Gautam } \\
\text { Chopra }\end{array}$ & 3 & $\begin{array}{l}\text { proposes } \\
\text { some alg. for } \\
\text { various } \\
\text { applications } \\
\text { of cooperative } \\
\text { communicatio } \\
\text { n. }\end{array}$ \\
\hline $\begin{array}{l}\text { Internationa } \\
1 \text { Journal of } \\
\text { Future } \\
\text { Generation } \\
\text { Communica } \\
\text { tion and } \\
\text { Networking } \\
\text { Vol.6, No.5 } \\
\text { (2013), } \\
\text { pp.157-166 }\end{array}$ & $\begin{array}{l}\text { Cooperat } \\
\text { ive } \\
\text { Commun } \\
\text { ication: } \\
\text { New } \\
\text { Trend in } \\
\text { Wireless } \\
\text { Commun } \\
\text { ication }\end{array}$ & $\begin{array}{l}\text { P. K. } \\
\text { Kharat, } \\
\text { J. } \\
\text { D.Gavad } \\
\text { e }\end{array}$ & $\begin{array}{l}201 \\
3\end{array}$ & $\begin{array}{l}\text { This paper } \\
\text { analyses the } \\
\text { different steps } \\
\text { in cooperative } \\
\text { communicatio } \\
\mathrm{n} \text { and various } \\
\text { protocols } \\
\text { available in } \\
\text { cooperative } \\
\text { communicatio } \\
\mathrm{n} \text {. }\end{array}$ \\
\hline $\begin{array}{l}\text { Internationa } \\
1 \text { Journal of } \\
\text { Computer } \\
\text { Science \& } \\
\text { Engineering } \\
\text { Survey } \\
\text { (IJCSES) } \\
\text { Vol.2, } \\
\text { No.4, } \\
\text { November } \\
2011\end{array}$ & $\begin{array}{l}\text { A survey } \\
\text { on co - } \\
\text { operative } \\
\text { diversity } \\
\text { and its } \\
\text { Applicati } \\
\text { ons in } \\
\text { various } \\
\text { wireless } \\
\text { networks }\end{array}$ & $\begin{array}{l}\text { Gurpreet } \\
\text { Kaur, } \\
\text { ParthaPr } \\
\text { atim } \\
\text { Bhattach } \\
\text { arya }\end{array}$ & $\begin{array}{l}201 \\
3\end{array}$ & $\begin{array}{l}\text { This paper } \\
\text { explains } \\
\text { about energy } \\
\text { consumption } \\
\text { and lifetime } \\
\text { of sensor } \\
\text { network and } \\
\text { their impact } \\
\text { on } \\
\text { cooperative } \\
\text { communicatio } \\
\text { n. Also it } \\
\text { highlights } \\
\text { various } \\
\text { applications } \\
\text { of cooperative } \\
\text { communicatio } \\
\text { n. }\end{array}$ \\
\hline $\begin{array}{l}\text { Journal of } \\
\text { Engineering } \\
\text { Science and } \\
\text { Technology } \\
\text { Review } 3 \\
\text { (1) (2010) } \\
184-187\end{array}$ & $\begin{array}{l}\text { Cooperat } \\
\text { ive } \\
\text { Diversity } \\
\text { in } \\
\text { Wireless } \\
\text { Network } \\
\text { s }\end{array}$ & $\begin{array}{l}\text { A. } \\
\text { Mahmoo } \\
\text { d }\end{array}$ & $\begin{array}{l}201 \\
0\end{array}$ & $\begin{array}{l}\text { This paper } \\
\text { analyses } \\
\text { various } \\
\text { signaling } \\
\text { methods in } \\
\text { cooperative } \\
\text { communicatio } \\
\mathrm{n} \text { and their } \\
\text { performance. }\end{array}$ \\
\hline $\begin{array}{l}\text { IEEE } \\
\text { communica } \\
\text { tions } \\
\text { magazine,O } \\
\text { ctober }\end{array}$ & $\begin{array}{l}\text { Cooperat } \\
\text { ive } \\
\text { Commun } \\
\text { ication in } \\
\text { Wireless } \\
\text { Network } \\
\text { s }\end{array}$ & $\begin{array}{l}\text { Aria } \\
\text { Nosratini } \\
\text { a, } \\
\text { Ahmadre } \\
\text { zaHeday } \\
\text { at, Todd } \\
\text { E. } \\
\text { Hunter }\end{array}$ & $\begin{array}{l}200 \\
4\end{array}$ & $\begin{array}{l}\text { This paper } \\
\text { explains } \\
\text { about the } \\
\text { basics of } \\
\text { cooperative } \\
\text { communicatio } \\
\text { n and } \\
\text { extensively } \\
\text { explains } \\
\text { coded } \\
\text { communicatio } \\
\text { n. }\end{array}$ \\
\hline
\end{tabular}

\section{OPERATION OF COOPERATIVE COMMUNICATIONS}

Before implementing cooperative communication, one needs to find the conditions when cooperation can be enabled, or the regions where the cooperation is beneficial.
Another important feature to be identified is the relay (helpers/optimal helpers). The source node maintains a CoopTable, by overhearing the transmission of other nodes. And then based on the entries in the CoopTable, the source node decides whether a packet should be transmitted through direct or indirect link, and to identify the optimal helper (relay).

\subsection{Steps to Implement Cooperation}

\subsubsection{Neighbor Maintenance Step}

Each node (S) in the cluster will broadcast at a regular interval, a COR (Cooperative Request). This will be received by all the neighboring nodes $(\mathrm{NN})$ which are within the transmission range. Now there are two options: one node which has received this COR will cooperate and another might not (due to its own traffic or energy constraints). If it is ready to cooperate, it sends an AOC (Agree On Cooperation), along with its user ID. This is depicted in Figure 3. The requesting nodes will store the IDs of cooperating nodes, terming it a "neighbor set".
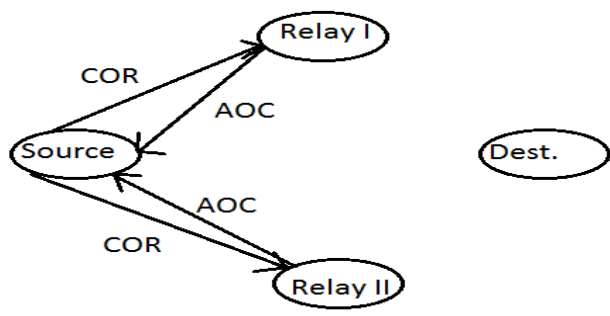

COR : COOPERATIVE REQUEST AOC: AGREE ON COOPERATION SOURCE, DEST., RELAY I AND II: INDEPENDENT SYSTEMS

Figure 3: Neighbor Maintenance Step

\subsubsection{Information Exchange Step}

When AOC is received by transmitting node, it plans to transmit the information. The cooperating node, may be free or be heavily occupied with its own assignments. To check if the node is ready to receive the information, the requesting node will send TR (Transmission Request). If it is ready to receive information, it will send the necessary information, as in Figure 4.
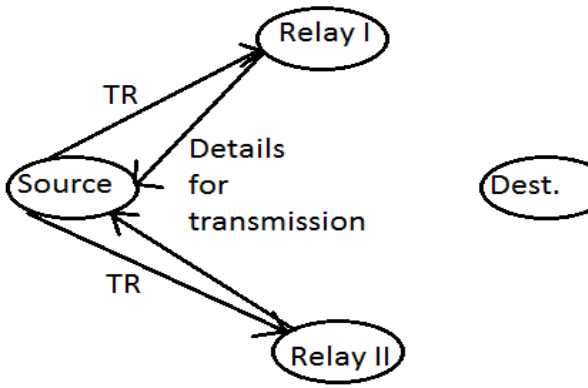

TR: TRANSMISSION REQUEST

SOURCE, DEST., RELAY I AND II: INDEPENDENT SYSTEMS

Figure 4 Information Exchange Step

\subsubsection{Local Distribution Setup}

After all these, the node is selected and power/data is allocated based on relay algorithms. Data is transmitted to each of the selected nodes and thus, cooperation is achieved and established (as in Figure 5). 


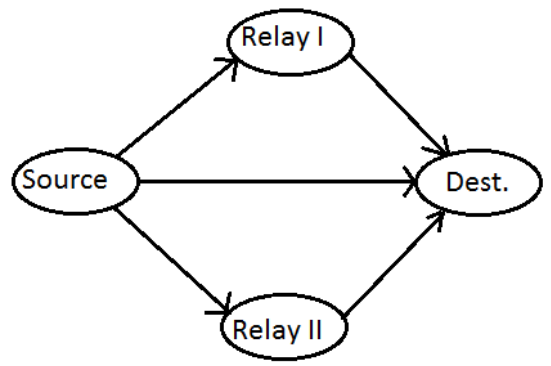

SOURCE, DEST., RELAY I AND II: INDEPENDENT SYSTEMS

\section{Figure 5: Local Distribution Step}

There are multiple transmission techniques like CoopMAC, DistributedMAC, etc. One of them is chosen depending on the source and the relay and the way the relay responds to the COR or TR.

\section{BASICRELAYING PROTOCOLS}

Once a transmission technique is selected, the cooperative transmission protocol should also decide if a relay should always forward the message from source or not. When the relay always forwards the message, this is referred as fixed relaying. There are other adaptive relaying schemes (ondemand relaying, selective relaying etc.).

Generally, one can realize cooperative communication by either single relay or multiple relays per user. Anyhow, how the relays manipulate the signals of the user differentiate the modes of transmission.

AMPLIFY AND FORWARD: The helpers (relay nodes) receive, amplify, and forward the signal from source node to destination node.

DECODE AND FORWARD: Helpers (Relay nodes) first decode and estimate the received signal from source code and then transmit the estimated data to destination node.

COMPRESS AND FORWARD: Helpers transmit a quantized and compressed version of the received message. So, the destination node will perform the reception functions by combining the received message from source and its quantized and compressed version from relay.

\section{COOPERATIVE RELAYING PROTOCOLS}

The types of relaying protocols are tabulated in Figure 6.

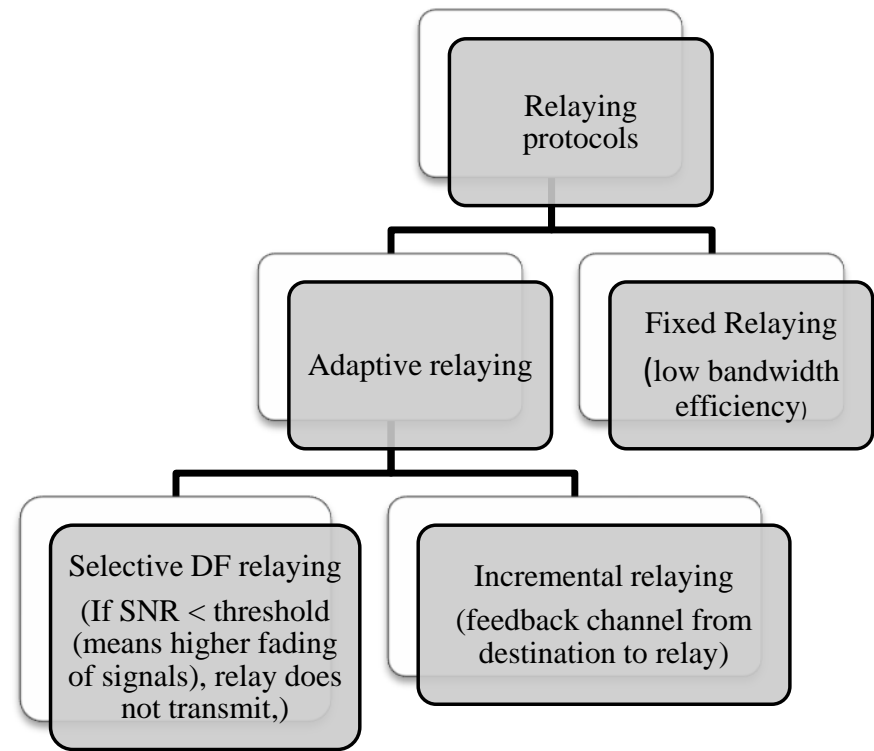

Figure 6 Types of Relaying protocols

In fixed relaying, the channel resources are divided in a fixed/deterministic nature. The processing at relay differs according to the employed protocols. The below table, Table 2 , enlists and describes the fixed relaying/cooperation strategies:

Table 2: Types of Fixed Relaying

\begin{tabular}{|c|c|}
\hline Type & Description \\
\hline \multirow[t]{2}{*}{ Fixed AF } & $\begin{array}{l}\text { (Single Relay) } \\
\text { Relay scales the received version and } \\
\text { transmits its amplified version to the } \\
\text { destination }\end{array}$ \\
\hline & $\begin{array}{l}\text { (Multi Relay) } \\
\text { Occurs in two stages: } \\
\rightarrow \text { Each relay forwards the source's signal to } \\
\text { destination } \\
\rightarrow \text { Each relay forwards a combined signal } \\
\text { from source and previous relays }\end{array}$ \\
\hline \multirow[t]{2}{*}{ Fixed DF } & $\begin{array}{l}\text { (Single Relay) } \\
\text { Decode the received signal at relay, re- } \\
\text { encode it and transmit to receiver }\end{array}$ \\
\hline & $\begin{array}{l}\text { (Multi Relay) } \\
\text { Relay combines the signals received from } \\
\text { previous relays along with the one received } \\
\text { from source }\end{array}$ \\
\hline
\end{tabular}

Fixed relaying is easy to implement, but suffers from low bandwidth efficiency (due to allocation of half of the channel resources to relay).

In adaptive relaying the inefficiency is overcome in two different ways, which is discussed in the below table, Table 3:

Table 3: Types of Adaptive Relaying

\begin{tabular}{|c|l|}
\hline Type & \multicolumn{1}{|c|}{ Description } \\
\hline $\begin{array}{c}\text { Selective } \\
\text { DF }\end{array}$ & $\begin{array}{l}\text { Relay decodes the received signal and } \\
\text { forwards decoded information to the } \\
\text { Relaying }\end{array}$ \\
& $\begin{array}{l}\text { destination, if the SNR of a signal at the } \\
\text { relayceeds a certain threshold }\end{array}$ \\
\hline
\end{tabular}




\begin{tabular}{|l|l|}
\hline $\begin{array}{c}\text { Increment } \\
\text { al Relaying }\end{array}$ & $\begin{array}{l}\text { In incremental relaying, there is a feedback } \\
\text { channel from the destination to the relay. } \\
\text { The } \\
\text { Destination sends an acknowledgement to } \\
\text { the relay if it was able to receive the } \\
\text { source's message correctly. (Good spectral } \\
\text { efficiency then Selective DF Relaying) }\end{array}$
\end{tabular}

\section{VARIOUS APPLICATIONS OF COOPERATIVE COMMUNICATION \\ 6.1 Wireless Ad-Hoc Networking}

An Ad-Hoc network is a self-organizing network without any centralized infrastructure. This network allows for seamless joining or leaving of the nodes. These are used in military and civilian communication applications.

\subsection{Wireless Sensor Networking}

Lifetime of a sensor network is limited by the energy of the nodes and the battery life of the sensor. Cooperative relaying can be used in routing process so that better communication links can be selected and hence, battery power can be saved.

\subsection{Cognitive Radio}

A cognitive radio is an intelligent radio that can be programmed and configured dynamically. Its transceiver is designed to use the best wireless channels in its vicinity.

In cognitive radio system, secondary users can utilize the resources which are employed forlicensed primary users. When primary users want to use their licensed resources, secondary users have to vacant these resources. Thus, secondary users have to constantly sense the presence of primary user. Probability of false alarming can be reduced with the help of spatially distributed nodes, which thus improve the channel sensing reliability by sharing the information

\subsection{Agricultural Applications}

To enhance the efficiency and growth of cultivations, cooperative communication over wireless sensor networks can be used. Using these networks it is possible to effect a punctual and real time monitoring that is useful to know the different microclimates that can be present in cultivations.

Another interesting agricultural application is inherent to irrigation management. Water usage can be controlled in a more efficient and economical way by monitoring moisture on soil, air humidity and weather forecasting.

Other goals of the system are frost detection and warning and, as before, pesticide application and disease detection. Generally, crop management, lowering costs and increasing quality is in the scope of applying sensors network technology to agriculture.

\subsection{Logistics}

Inventory control is a major problem for big companies. Management of assets (pieces of equipment, machinery, different types of stock or products) can be a predicament. The problem is highly distributed, as these companies expand all over the world.

A possible application is related to warehouse and storage management of barrels. The concept is that sensor nodes attached to barrels will be capable of locating nearby objects (nodes) (other barrels), detecting their content and alerting in case of incompatibility with their own (danger of a chemical reaction), aging effects of the enclosure etc. This will enhance safety and guarantee product quality.

\section{COOPERATIVE COMMUNICATION IN HEALTH CARE}

Biomedical industry is the mostdynamic, critical and challenging among all the industries.Medical information has a higher priority in all communication networks. By applying of cooperative communication to a hospital, one can centralize all patient and doctor details, thereby ensuring data availability and sharing.

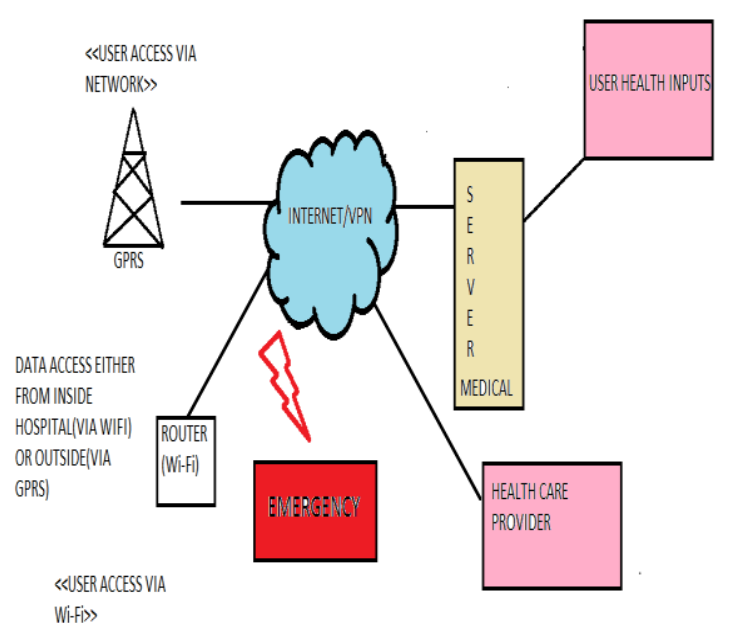

\section{Figure 7 Basic Network architecture of HealthCare Application}

Figure 7 depicts the network architecture of HealthCare application. It gives a high level description of the necessary components in HealthCare application. The user health details (acquired by some sensors) are stored in centralized medical server. The overall network can be hosted in Internet or as a VPN. Also note that this can be connected to emergency medical and other services like blood banks, ambulances, pharmaceuticals, organ banks etc. A medical service provider (hosted in another server) controls and coordinates all the data and the services provided by the HealthCare application.

All these data can be accessed by authorized personnel (doctors, nurses and patients) via either WiFi (from inside of the hospital) or via GPRS (from outside of the hospital). Proper authentication, authorization and confidentiality should be maintained.

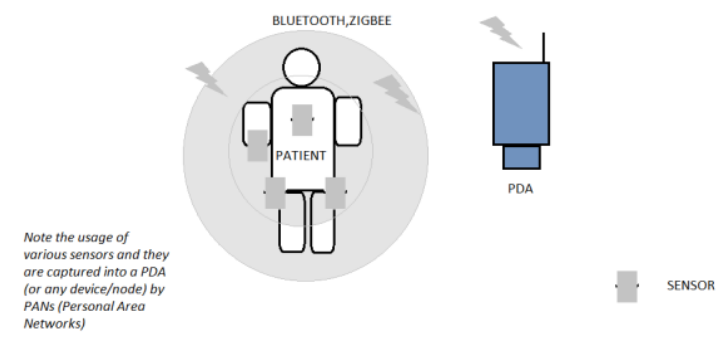

Figure 8 Data acquisition from Patient

Sensors, which acquire data, can be categorized in different levels: 


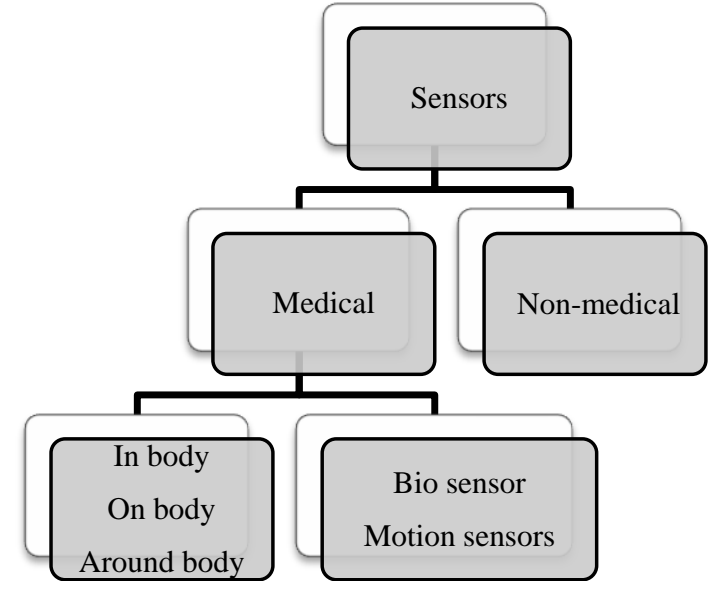

Figure 9 Categories of Sensors

Data acquired from the sensors, as shown in Figure 8, can either be wave-form real time stream, real-time parameter measurement stream or video stream. They are appropriately monitored and handled by the responsible persons.

A logical connection between all the nodes of the HealthCare application network is a star, multi-hop, cluster based architecture.

Performance Metrics:
1. Packet Delivery Ratio
2. Self-organizing (Ad-hoc)
3. Network life time
4. Interference

\subsection{Routing Protocols}

Major challenge is the acquisition of sensor data of patients and their transmission. Two major protocols that can be used here are:

1. CICADA (Cascading Information Retrieval by Controlling Access with Distributed Slot Assignment Protocol): The protocol sets up a network tree in a distributed manner. This tree structure is subsequently used to guarantee collision free access to the medium and to route data towards the sink.

2. DQBAN (Distributed Queuing Body Area Networks): The main idea is to amalgamate fuzzy logic system in each body sensors to deal with multiple cross layer input variables of dissimilar nature and independent manner. It guarantees low energy consumption and suitable under coexisting scenarios. DQBAN MAC model has shown to achieve higher reliability than other possible MAC implementation.

\subsection{More Details}

A basic logical application of HealthCare application in the figure 10 has the below components for extra services:

1. An Analysis Tool might be used, which can enable a hospital or a group of hospitals to analyze the mortality rate.

2. Private forum, wherein doctors can share the knowledge of their previous cases to improvise their treatments.
Integrity and confidentiality is maintained by restricting the details of one department to be forbidden for another.

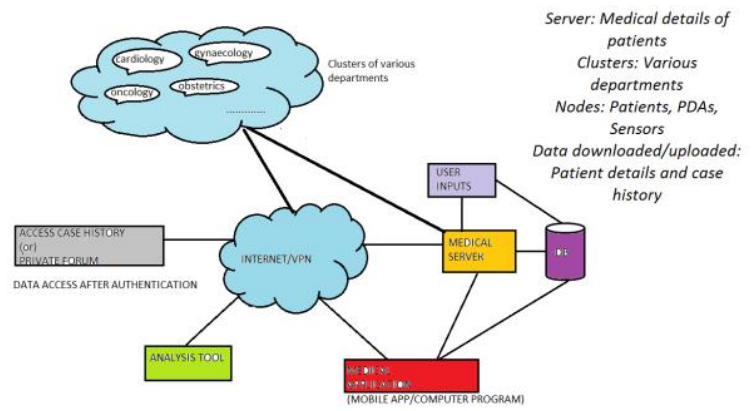

Figure 10 Logical architecture of HealthCare application

This model can be extended to multiple hospitals (i.e. a cluster of hospitals).

Merits:

1. Maintaining patient records

2. Self-analysis of doctors

3. Higher curing rate

4. Analysis of hospital (to identify curing rate)

5. Reduction in doctor's visit to patient; all data updated in the network, shared within the cluster. If any abnormalities seen, doctor will visit.

6. If a patient revisits, his history can be easily downloaded and understood.

\section{Challenges}

1. Complexity in identifying the routing protocols

2. Consistent medical QoS

3. Efficient radio and bandwidth allocation

\section{CONCLUSION}

Usage of cooperative communication can allow one to completely computerize the HealthCare application, thereby revolutionizing the medical industry. One faces major challenges in allocation of resources and the protocol selection. The objective of this paper is to give an insight on cooperative communication and to provide a high-level description of the network architecture and logical architecture that can be implemented fora health care application (for a hospital cluster) in a cooperative network.

\section{REFERENCES}

[1] S.R.Dikondwar, Gautam Chopra "Advanced Applications using Cooperative Wireless Networks", Conference on Advances in Communication and Control Systems 2013 (CAC2S 2013)

[2] P. K. Kharat and J. D.Gavade "Cooperative Communication: New Trend in Wireless Communication", International Journal of Future Generation Communication and Networking Vol.6, No.5 (2013), pp.157-166

[3] Aria Nosratinia, Ahmadreza Hedayat, Todd E. Hunter "Cooperative Communication in Wireless Networks", 
IEEE communications magazine, October 2004

[4] Gerhard Kramer, Ivana Mari'c and Roy D. Yates, "Cooperative Communications", Foundations and Trendsin Networking Vol. 1, Nos. 3-4 (2006) 271-425

[5] ArnabChakrabarti, BehnaamAazhang

AshutoshSabharwal, "COOPERATIVE COMMUNICATIONSFundamental Limits and Practical Implementation"

[6] Yao-Win Hong, Wan-Jen Huang, Fu-Hsuan Chiu, and C.-C. Jay Kuo "Cooperative Communications in resource-constrained wireless networks", IEEE signal processing magazine, May 2007

[7] Qian (Clara) Li, Rose Qingyang, Yi Qian, Geng WU, "Cooperative Communications for Wireless Network: Techniques and Applications in LTE-advanced Systems"

[8] Gurpreet Kaur and Partha Pratim Bhattacharya, "A survey on cooperative diversity and itsApplications in various wireless networks", International Journal of Computer Science \& Engineering Survey (IJCSES) Vol.2, No.4, November 2011

[9] A. Mahmood, "Cooperative Diversity in Wireless Networks", Journal of Engineering Science and Technology Review 3 (1) (2010) 184-187

[10] JuhiGarg, Priyanka Mehta and Kapil Gupta, "A Review on Cooperative CommunicationProtocols in Wireless World", International Journal of Wireless \& Mobile
Networks (IJWMN) Vol. 5, No. 2, April 2013

[11] G. M. Tamilselvan , A. Shanmugam , R. Kalaipriya, G. R. Dhurgavathi and G. Ranganayaki, "DQBAN SYSTEM MODEL FOR WIRELESS BODY AREA NETWORKS", International Journal of Wireless Communications and Networking 3(1), 2011, pp. 27-32"

[12] L.Mareeswari, V.Kalaivani, V.Anusuya Devi, "Secure, Reliable and an Energy Efficient Protocol for Wireless Body Sensor Network in Medical Applications", International Journal of Computer Applications ${ }^{\circledR}$ (IJCA) (0975 - 8887) International Conference on Simulations in Computing Nexus, ICSCN-2014

[13] Latre, B.Braem, B. ; Moerman, I. ; Blondia, C. ; Reusens, E. ; Joseph, W. ; Demeester, P. "A Lowdelay Protocol for MultihopWireless Body Area Networks", Mobile and Ubiquitous Systems: Networking \&Services, 2007. MobiQuitous 2007

[14] Menghwar, G.D. Mecklenbrauker, C.F., "Cooperative versus non-cooperative communications", Computer,Control and Communication, 2009. IC4 2009

[15] MatteoLucchi, "Cooperative Communication and Distributed Detection in Wireless Sensor Networks", Dottorato di Ricerca in IngegneriaElettronica, Informatica e delleTelecomunicazioni - XX Ciclo SSD: ING-INF/03 - Telecomunicazioni"

[16] http://wides.usc.edu/research/cooperativecommunications-and-sensor-networks/ 